\section{Assessing food dietary intakes in Japanese-Brazilians using factor analysis}

\author{
Avaliação da ingestão de alimentos por \\ nipo-brasileiros utilizando análise fatorial
}

\begin{abstract}
1 Departamento de Medicina
Preventiva, Universidade

Federal de São Paulo, São

Paulo, Brasil.

2 Faculdade de Saúde

Pública, Universidade de São

Paulo, São Paulo, Brasil.

${ }^{3}$ Faculdade de Medicina de

Ribeirão Preto, Universidade

de São Paulo, Ribeirão Preto,

Brasil.

Correspondence

S. G. A. Gimeno

Departamento de Medicina

Preventiva, Universidade

Federal de São Paulo.

Rua Borges Lagoa 1341, São

Paulo, SP 04038-034, Brasil.

sgag@uol.com.br
\end{abstract}

Suely Godoy Agostinho Gimeno 1

Solange Andreoni 1

Sandra Roberta Gouvea Ferreira 2

Laércio Joel Franco 3

Marly Augusto Cardoso 2

\section{Introduction}

We describe the use of factor analysis for assessing food habits in Japanese-Brazilians. Dietary data from 1,283 participants of a cross-sectional study were used. Besides statistical criteria, we also used the conceptual meaning of identified profiles to obtain scores for dietary patterns (Japanese or Western profile). Paired Student t test, linear regression and Poisson models were used to verify the existence of relationship between these scores and generation, body mass index (BMI), waist circumference and presence of metabolic syndrome, respectively. First generation subjects had higher mean Japanese profile scores and lower Western profile scores than those of second generation. The Western dietary pattern was associated with BMI $(p=0.001)$, waist circumference $(p=0.023)$ and metabolic syndrome $(p<0.05)$. We concluded that these scores were able to discriminate subjects who maintained their traditional Japanese lifestyle or otherwise, and that the incorporation of a Western lifestyle is associated to high values of BMI, waist circumference and presence of metabolic syndrome.

Food Habits; Nutritional Epidemiology; JapaneseBrazilians; Statistical Factor Analysis
Identifying patterns of dietary intake can explain, at least in part, the differences observed in the incidence of chronic diseases such as obesity, diabetes mellitus, arterial hypertension, obesity, cardiovascular diseases and various types of cancer, within and between populations 1 .

It is known for instance, that the prevalence of diabetes mellitus type 2 , metabolic syndrome and cardiovascular diseases among Japanese immigrants living in the Americas is greater than rates found among individuals living in their native Japan. This suggests that the effect of environmental factors, especially those related to life style, independently of genetic predisposition, play a fundamental role in the development of these diseases 2,3,4. Pierce et al. ${ }^{5}$ stated that Japanese immigrants who retained their traditional life style appeared to be less susceptible to chronic diseases such as diabetes mellitus compared to individuals who had assimilated Western habits. The same authors highlighted that habitual diet may be a key indicator of degree of Westernization of these groups. In addition, consumption of a diet rich in animal fats and refined sugar is known to be associated to high body adiposity, an important ethiopathogenic factor underlying these diseases 5,6.

Different statistical techniques can be employed to identify patterns of dietary intake in groups of individuals or among whole popula- 
tions. One such important technique is factor analysis - a multivariate technique which summarizes information contained in a set of observable variables using some variables which are "non-observable directly", called factors, with a minimal loss of information. The main aims of this approach are: (a) to obtain a reduced set of characteristics (factors), preferably noncorrelated, from a large set of variables (the majority of which are intercorrelated);(b) to create scores or indexes based on variables which, conceptually, measure similar attributes. The main rationale for using factor analysis is the impossibility of observing (measuring) these factors directly 7,8 .

Against this background, the main aim of the present study was to provide a step-by-step description of the application of factor analysis and interpretation of the results obtained, for information on habitual food intake in the process of identifying dietary patterns. The relationships between the patterns identified, anthropometric variables, and presence of metabolic syndrome were then examined. This study was based on dietary data from a community of JapaneseBrazilians.

\section{Material and methods}

An epidemiological transversal study was conducted among members of the immigrant Japanese community and their descendents living in the Municipal district of Bauru, São Paulo State, Brazil (second phase of study performed by the Japanese-Brazilians Diabetes Study Group JBDSG - of the Federal University of São Paulo). Details on the methodology employed have been described elsewhere 3,6 . Briefly, the aim of this investigation was to estimate the prevalence of diabetes mellitus and associated diseases among this group of individuals. Data collection took place between 1999 and 2000 in 1,330 subjects aged $\geq 30$ years of both genders, first (born in Japan) or second generation Japanese (born in Brazil, offspring of first generation Japanese) who agreed to take part in the study $(76 \%$ of the total population of Japanese and descendents with the characteristics of interest living in Bauru). Data collection was performed by interviewing the Japanese-Brazilians using a standardized questionnaire (sociodemographic data, medical history, smoking, physical leisure activity and habitual diet) and submitting subjects to a physical exam (blood pressure and anthroprometry) and laboratory assays (glycemia, lipid profile etc.). The Research Ethics Committee of the Federal University of São Paulo approved the study and all participants signed a term of free and informed consent.

Food intake was measured using the food frequency questionnaire (FFQ) developed and validated for use in populations of Japanese ancestry 9 . Dietary information (habitual consumption and food frequency for the previous year) was gathered for 1,283 subjects $(94.6 \%$ of the total Japanese-Brazilian participants in the study). The FFQ comprised 122 food items and questions on use of seasoning/spices, frequency of visible fat intake and type of fat used for cooking. The Dietsys 4.01 program (National Cancer Institute, Bethesda, USA) was employed to calculate the nutrients in the diet. The present analysis included the following food groups (defined based on similarity in chemical composition): (a) milk and derivatives (full or skimmed, cheese and yoghurt), (b) red meats (beef or pork), (c) viscera (heart, liver or gizzards), (d) processed meats and sausages (sausages, frankfurters, hams or mortadella),(e) poultry (poultry in general, chicken or turkey), (f) fish (fish in general, sashimi - raw fish -, chikuwa - fish cakes - or shrimp), (g) eggs, (h) vegetables (greens and legumes in general), (i) fruit (oranges, papaya, banana, apple, pear, kaki, water melon, mango, pineapple, honeydew melon, kiwi, guava, grapes, strawberries, peaches, plums, avocado, fruit salad and fresh fruit juices), (j) soy and derivatives (soy bean, tofu, soymilk - tonyu), (k) miso (traditional bean paste made with fermented soy base), (l) breads and other cereals (bread in general or biscuits, rice, noodles), (m) sweet deserts and sugary foods (sugar, deserts in sauce or syrup, jam, ice-cream, cakes, sweet tarts, sweets, chocolates and other recipes containing sugar), (n) soft drinks (soft drinks in general, including low calorie/sugar products - diet/ light), (o) beer (containing alcohol), (p) wine (red or white) and (q) sake (traditional Japanese rice wine).

Physical exams and biochemical assays were performed at the Hospital for Rehabilitation of Craniofacial Anomalies in Bauru. Body weight was measured in kilograms using platform-type anthropometric scales (Filizola, São Paulo, Brazil) with a $200 \mathrm{~kg}$ capacity and accurate to the nearest $100 \mathrm{~g}$, placed on a level surface and calibrated between each weighing session. Subjects wore the least clothing possible and were weighed with shoes removed. Height readings were taken on a wall-mounted manual stadiometer (Sanny, São Paulo, Brazil) with a $2 \mathrm{~m}$ capacity and accurate to the nearest $1 \mathrm{~cm}$. Individuals were measured barefoot with gluteus, trunk and head against the wall, which had no skirting board, on an even smooth surface, and with arms held alongside the body. The body mass index (BMI) was cal- 
culated by dividing weight $(\mathrm{kg})$ by height $(\mathrm{m})$ squared. Waist circumference was measured using a non-stretch metric tape measure at the level of the umbilical scar, to the nearest $0.1 \mathrm{~cm}$. These measurements were taken with individuals standing erect with abdomen relaxed, arms held to the sides and feet together.

Systolic (SBP) and diastolic (DBP) arterial blood pressures were taken after $10 \mathrm{~min}$ rest in the sitting position by trained physicians using a model HEM712C automatic digital device by Omron (Omron Health Care, USA) with cuff adjusted for brachial circumference. Three readings were taken, where the final value was the arithmetic mean of the last two measurements, and values expressed in millimeters of mercury (mmHg).

Glucose and lipid profile (total cholesterol, fractions and triglycerides) were determined based on the first sample (minimum 10-hour fast) of venous blood. Blood glucose was determined by the glycol-oxidase method in a second sample collected two hours after oral glucose (75g) overload. Glucose overload was performed only in individuals who reported no previous diagnosis for diabetes mellitus, who were known diabetics in use of antidiabetic medication, and in those presenting with fasting capillary glycemia $\geq 200 \mathrm{mg} / \mathrm{dL}$. Capillary glycemia was measured using a glucometer (Glucostix/Glucometer System, Leverkusen, Germany). Lipoprotein levels were determined using enzyme kits.

Metabolic syndrome was diagnosed based on International Diabetes Federation criteria 10, according to which "sick" individuals are those with central obesity (waist circumference $\geq 90$ or $80 \mathrm{~cm}$ for male and female Asians, respectively) and at least two of the following components: fasting glycemia $\geq 100 \mathrm{mg} / \mathrm{dL}$, triglycerides $\geq 150 \mathrm{mg} / \mathrm{dL}$, $\mathrm{HDL}<40 \mathrm{mg} / \mathrm{dL}$ or $50 \mathrm{mg} / \mathrm{dL}$ (men or women, respectively) and systolic/diastolic arterial pressure $\geq 130 / 85 \mathrm{mmHg}$.

\section{Data analysis}

Prior to employing factor analysis, it was necessary to verify whether prerequisites for use of the technique were satisfied 7,8. The technique can be applied to: (a) quantitative variables measured on an interval or value scale (the case for consumption of different food groups, measured in grammes); (b) data obtained in subjects selected using a probabilistic procedure (in the case of Japanese-Brazilians, no form of probabilistic selection was used since this investigation included the entire population of JapaneseBrazilian residents of Bauru aged $\geq 30$ years, of both genders, that were first or second genera- tion $-24 \%$ non-participants -, a fact which does not rule out use of the technique); (c) variables which have a linear interrelationship (verified by scatter plots).

Factor analysis was preceded by assessment of the magnitude of correlation among the food groups by calculating Pearson's linear correlation coefficient. The adequacy of data for factor analysis was assessed by the Kaiser-Meyer-Olkin measure (KMO; values close to 1 indicate good adequacy).

Initially, factor analysis was carried out on principle components (considering the total variance of the data) with no manner of restriction in terms of number of factors to be retained in the model (i.e. factors identifying different profiles of food intake). This strategy enables exploring the possibilities of data reduction while allowing preliminary assessment of the number of factors that can be retained.

The factor extraction procedure is based on capturing, in the first factor, the highest possible amount of common variance of the data (communality). Similarly, subsequent factors capture the maximum remaining amount until no further common variability is left 7,8 . For this procedure, only subjects with complete information on all variables can be included in the analysis (for this study, 866 Japanese-Brazilians $-67.5 \%$ of those answering the FFQ had full data for the 17 food groups investigated)

The results of the analysis provide researchers with the following information: (a) the eigenvalues (values $\geq 1$ indicate a good capacity of the factor to accumulate part of the total common variance and suggests that this can be retained in the model - the higher this value the greater the importance of the factor 7,8); (b) proportion of total common variability captured by the factor (higher values indicate greater importance); (c) loading factor (indicates the correlation of each variable - food groups - with the factor identified); (d) proportion of the variability which is specific to the variable itself and not shared with the others (uniqueness, the higher its value the lesser the importance of the variable in defining the factor). Assessment of these results, in conjunction with the graphs based on them (factor loadings for the two principle profiles 11; screeplot - eigenvalues vs. number of factors - the point of inflection of the curve of the function indicates the number of factors that can be retained in the analysis 12 ) and the interpretation of the conceptual meaning of the identified profiles enables the number of factors that should be retained in the model to be determined. Thus, the present study opted to repeat the procedures while maintaining the two 
principle factors in the analysis (Japanese and Western profiles).

In order to obtain an easily interpretable model, the correlation matrix was rotated (orthogonal rotation, varimax). This strategy, constituting a new transformation of the data (rotates reference axes of the factors about the origin until reaching an ideal position), allows the obtention of factors which are independent from each other, and reduces the possible ambiguities observed in the preliminary analysis (variables - food groups which may have substantial factor loadings on several factors simultaneously). The rotation is especially useful when the variables are highly intercorrelated (which may be the case for those pertaining to food intake).

After rotation, those food groups responsible for the greatest factor loading for each factor are identified (dietary variables which conceptually explain the factor, i.e. those with greater loading). Since the model obtained proved a good fit for the aims of the study, scores defining each factor were generated, i.e. Japanese pattern (factor 1) and Western pattern (factor 2). These scores represented the extent to which each individual differed from the mean for each score (in standard deviations), whereby higher scores indicated greater "adherence" to the pattern.

Given that these scores ("standard") were based on the use of data from subjects with complete information (in this case, $67.5 \%$ of Japanese-Brazilians who answered the FFQ), "new scores" were created for factors 1 and 2 based on the total sample of subjects $(\mathrm{N}=1,283)$. For this purpose, standardized variables were created (vp) representative of those food groups with greatest loading for each factor $\left(v p=\frac{\left(x_{i}-\tilde{x}\right)}{s}\right.$, where $\mathrm{x}_{\mathrm{i}}$ is the value observed for the $\mathrm{i}$-th individual for intake of a given food group, while $\bar{x}$ and $s$ represent the mean and standard deviation of intake of this food group, respectively) and the mean of the values of those standardized variables with greatest loading for each factor was calculated separately ("new score"). The mean values of these "new scores" were subsequently compared using Student's t test with values obtained by the conventional procedure ("standard"). The results showed no statistically significant differences between the values and therefore only scores defined by the "standard" method were used in the remaining steps of the analysis.

Finally, on the analysis of the discriminatory capacity of these scores (subjects that maintained their traditional habits and customs - Japanese pattern - from those who did not Western pattern), mean values attributed to both factors were compared by generation, using Student's $t$ test, assuming that first-generation indi- viduals had a greater tendency to maintain their traditions (greater mean score for factor 1), while their descendants (second generation) more readily incorporated a Western life style (greater mean score for factor 2). Multiple linear regression and Poisson models with robust variance were also used to examine the relationships of these scores (independent variables) with anthropometric variables (BMI, in $\mathrm{kg} / \mathrm{m}^{2}$ - dependent variable; or waist circumference in $\mathrm{cm}$ - dependent variable), and the presence of metabolic syndrome (yes $v s$. no) among subjects without diabetes (dependent variable; excluding those with diabetes mellitus to minimize the effect of reverse causality typically found in transversal studies), respectively, independently of gender, age (in years), generation, smoking (yes vs. no), years of schooling, leisure-time physical activity (sedentary vs. non-sedentary) or total calories in the habitual diet of subjects (confounding variables).

The Stata software, version 10.1 (Stata Corp., College Station, USA) was used for all stages of the analysis.

\section{Results}

Of the 1,283 Japanese-Brazilians with information on habitual food intake, 694 were women (54.1\%), 1,033 were second generation $(80.5 \%)$ and 750 had metabolic syndrome (58.6\%). Mean values (standard deviation) of age, BMI and waist circumference of these individuals were 57.1 years (12.4 years), $24.9 \mathrm{~kg} / \mathrm{m}^{2}\left(3.9 \mathrm{~kg} / \mathrm{m}^{2}\right)$ and $83.8 \mathrm{~cm}(10.4 \mathrm{~cm})$, respectively. Similar values were found (means or proportions) among the 866 subjects with full dietary information (whose data was used to obtain the score defining the profile of interest).

Values measured for central tendency, dispersion and position for food groups are shown in Table 1. Values of $r \geq 0.20$ (Pearson's linear correlation coefficient) were found for virtually all these variables, and the KMO value was 0.63 , indicating satisfactory adequacy of data for factor analysis.

The results from factor analysis (prior to rotation of the correlation matrix) allowed six distinct patterns of food consumption to be identified: (a) factor 1 (Japanese), defined by the consumption of soy and derivatives, miso (fermented soybased bean paste - traditional food in Japanese cuisine) and fish; (b) factor 2 (Western), characterized by consumption of sweet deserts, sugary foods and soft drinks; (c) factor 3, explained by diet of eggs, bread, processed meats and sausages, and red meat; (d) factor 4 , defined by in- 
Values for measurements of central tendency, position and dispersion of dietary variables (in grammes). Bauru, São Paulo, Brazil, 2000

\begin{tabular}{|c|c|c|c|c|}
\hline Food groups & $\begin{array}{c}\text { Mean } \\
\text { (standard deviation) }\end{array}$ & Median & 25th percentile & 75th percentile \\
\hline Milk derivatives & $177.60(122.53)$ & 169.5 & 75.40 & 234.10 \\
\hline Red meat & $311.9(296.00)$ & 248.60 & 164.20 & 369.60 \\
\hline Viscera & $1.73(3.44)$ & 0.20 & 0.00 & 2.00 \\
\hline Processed meats & $13.09(14.73)$ & 8.70 & 3.70 & 16.30 \\
\hline Poultry & $7.93(9.54)$ & 6.00 & 3.00 & 12.90 \\
\hline Fish & $19.76(20.92)$ & 13.40 & 6.70 & 25.50 \\
\hline Eggs & $11.45(14.36)$ & 8.60 & 4.00 & 17.10 \\
\hline Vegetables & $194.25(92.51)$ & 182.90 & 130.50 & 237.10 \\
\hline Fruit & 391.04 (295.95) & 331.50 & 194.10 & 506.5 \\
\hline Soy and derivatives & $56.59(99.56)$ & 20.50 & 7.50 & 59.60 \\
\hline Miso & $50.02(96.32)$ & 13.30 & 3.30 & 57.10 \\
\hline Breads and other cereals & $446.48(187.33)$ & 468.70 & 294.20 & 543.90 \\
\hline Desserts and sugary foods & 148.85 (193.04) & 91.20 & 40.40 & 185.00 \\
\hline Soft drinks & $97.36(177.73)$ & 28.60 & 0.00 & 114.30 \\
\hline Beer & 67.71 (199.10) & 0.00 & 0.00 & 15.00 \\
\hline Wine & $2.69(14.76)$ & 0.00 & 0.00 & 0.00 \\
\hline Sake & $2.40(19.54)$ & 0.00 & 0.00 & 0.00 \\
\hline
\end{tabular}

take of alcoholic beverages (beer, sake); (e) factor 5 , whose principal foods were poultry, viscera vegetable and fruit and; (f) factor 6 , with greater loading for milk-derived products and wine intake. The first two factors had eigenvalues $\geq 2$ and explained $29 \%$ of the total variability of the data, while the other four factors (eigenvalues $\geq 1$ and $<2$ ) combined, accounted for a further $31 \%$ of this variability.

Figure la shows that soy and miso intake accounted for the highest loadings for factor 1 and lowest loadings for factor 2 , while the inverse was found to be the case for consumption of soft drinks and sweet deserts, characterizing the two different food intake profiles: Japanese and Western, respectively. Although the data depicted in Figure $1 b$ indicates four food intake patterns, in line with the aims of this study, only two of the principle patterns were maintained in the other steps of the analysis (those with eigenvalues $\geq 2$ ).

Table 2 shows that, after rotation of the correlation matrix, factor 1 (Japanese) is largely explained by consumption of soy and derivatives, miso, fish and vegetables (responsible for the highest loading in the calculation of the score and having a factor loading $>0.48$ ), while sweet deserts, soft drinks, processed meat products and red meats characterized factor 2 (West- ern, factor loading $>0.50$ ). Notably, the groups bread and eggs (loading factor $>0.20$ ) were not considered "factor definers" given that their contributions were similar in both patterns (Japanese and Western).

Figure 2 depicts the distribution of scores according to the definitions of both patterns, by generation. It is evident that first-generation subjects had statistically greater values for factor 1 and lower values for factor 2 compared to values of second generation individuals. In addition, the multiple linear regression model (Table 3) revealed that the score values which defined the Western pattern (factor 2) correlated positively with BMI ( $\hat{\beta}=0.46 ; \mathrm{p}=0.001$ ) and waist circumference $(\hat{\beta}=0.88 ; \mathrm{p}=0.023)$, independently of gender, age, generation, smoking, leisure-time physical activity and total calorie intake of Japanese-Brazilians. This suggests that the higher the score (greater degree of incorporation of a Western lifestyle) the higher the value of these variables (indicators of generalized and central obesity, respectively). The representative score of the Western pattern was also positively associated with metabolic syndrome among subjects without diabetes mellitus (prevalence ratio = 1.16; 95\%CI: 1.04-1.30). 
Figure 1

Factor 1 and 2 loading values for different food groups (1a) and eigenvalues by number of factors defined on factor analysis (1b).

1a)

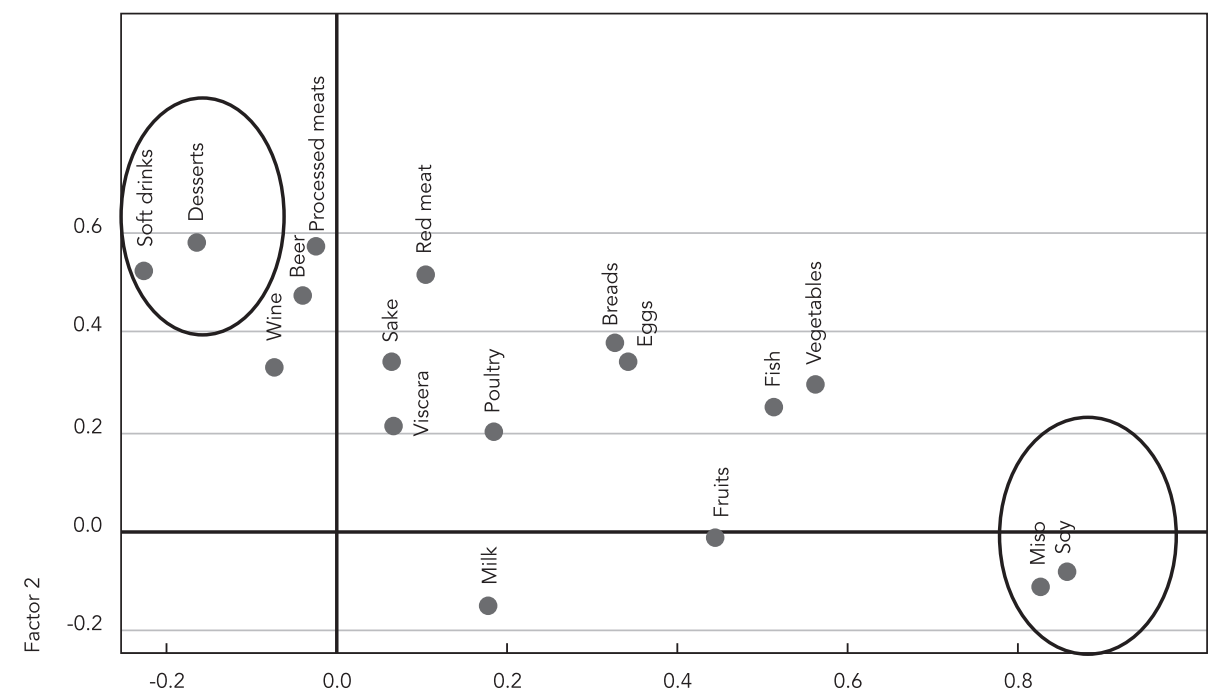

Factor 1

1b)

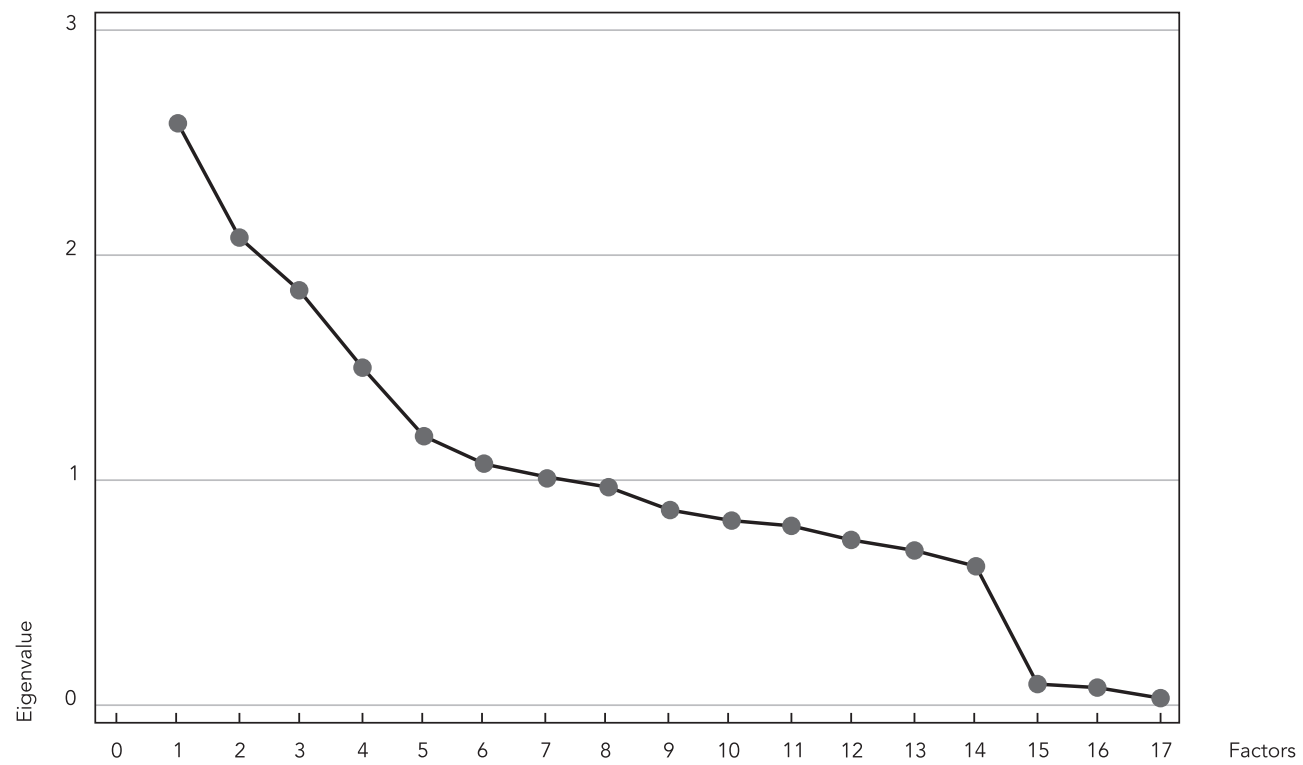


Factor loading and percentage variability of variables by pattern (before and after rotation) and food groups consumed by Japanese-Brazilians. Bauru, São Paulo, Brazil, 2000.

\begin{tabular}{|c|c|c|c|c|c|}
\hline \multirow[t]{2}{*}{ Food groups } & \multicolumn{2}{|c|}{ Factor loading before rotation } & \multicolumn{2}{|c|}{$\begin{array}{l}\text { Factor loading after rotation } \\
\text { (coefficients used for score) }\end{array}$} & \multirow[t]{2}{*}{$\begin{array}{l}\text { Variability of } \\
\text { variable (\%) }\end{array}$} \\
\hline & $\begin{array}{c}\text { Factor } 1 \\
\text { (Japanese) }\end{array}$ & $\begin{array}{l}\text { Factor } 2 \\
\text { (Western) }\end{array}$ & $\begin{array}{l}\text { Factor } 1 \\
\text { (Japanese) }\end{array}$ & $\begin{array}{l}\text { Factor } 2 \\
\text { (Western) }\end{array}$ & \\
\hline Milk derivatives & 0.09 & 0.06 & $0.09(0.03)$ & $0.07(0.03)$ & 95 \\
\hline Red meat & 0.31 & 0.43 & $0.10(0.02)$ & $0.51(0.21)$ & 72 \\
\hline Viscera & 0.27 & 0.08 & $0.25(0.09)$ & $0.11(0.05)$ & 95 \\
\hline Processed meats & 0.22 & 0.54 & $-0.03(-0.03)$ & $0.52(0.20)$ & 67 \\
\hline Poultry & 0.14 & 0.03 & $0.14(0.05)$ & $0.05(0.02)$ & 92 \\
\hline Fish & 0.59 & -0.12 & $0.60(0.22)$ & $-0.05(-0.03)$ & 67 \\
\hline Eggs & 0.42 & 0.25 & $0.34(0.12)$ & $0.30(0.14)$ & 76 \\
\hline Vegetables & 0.49 & 0.01 & $0.49(0.18)$ & $0.07(0.03)$ & 59 \\
\hline Fruit & 0.32 & -0.15 & $0.34(0.13)$ & $-0.11(-0.06)$ & 80 \\
\hline Soy and derivatives & 0.77 & -0.18 & $0.79(0.30)$ & $-0.08(-0.05)$ & 26 \\
\hline Miso & 0.76 & -0.18 & $0.78(0.29)$ & $0.08(-0.05)$ & 30 \\
\hline Breads and other cereals & 0.46 & 0.15 & $0.33(0.11)$ & $0.21(0.09)$ & 75 \\
\hline Dessert and sugary foods & 0.09 & 0.94 & $-0.02(-0.02)$ & $0.94(0.46)$ & 63 \\
\hline Soft drinks & 0.07 & 0.93 & $-0.05(-0.03)$ & $0.94(0.46)$ & 67 \\
\hline Beer & 0.07 & 0.03 & $0.07(0.02)$ & $0.04(0.02)$ & 77 \\
\hline Wine & 0.06 & -0.05 & $0.07(0.03)$ & $-0.15(-0.02)$ & 88 \\
\hline Sake & 0.13 & -0.06 & $0.13(0.05)$ & $-0.05(-0.03)$ & 88 \\
\hline Eigenvalue & & & 2.46 & 2.02 & \\
\hline Variability explained by factor (\%) & & & 16 & 13 & \\
\hline
\end{tabular}

\section{Discussion}

The results of previous studies conducted by the JBDSG show a high prevalence of diseases associated to the habits of Western life styles in this population of Japanese-Brazilians 3,6. The availability of clinical and dietary data from a population-based study performed using validated instruments represented an important opportunity to identify patterns of dietary intake in these subjects and to verify the presence of an association between these patterns and excess bodyweight, involved in the genesis of several metabolic and cardiovascular diseases.

In the present study employing factor analysis, two different dietary intake patterns were identified. The first pattern (called "Japanese"), predominantly consisting of foods such as soy and derivatives, fish and vegetables (typical components of a traditional Japanese diet) and, the second pattern (called "Western") characterized by habitual intake of sugary cakes and deserts, soft drinks, processed meats and sausages, and red meat. The scores produced by this analysis had a good capacity to discriminate first generation from second generation subjects. The statistically significant relationships found between score for Western profile, anthropometric variables and the metabolic syndrome confirmed the negative impact of incorporating Western habits and customs on the health of these subjects (assessed by habitual food intake) suggested by many researchers $1,2,3,4,5$.

Researchers for the World Health Organization \& Food and Agriculture Organization 13 have reported that dietary food intake patterns characterized by diets with a high energetic density and rich in fats (particularly saturated forms) and refined carbohydrates, allied with lower energy expenditure (sedentary lifestyle) are responsible (at least in part) for the rising global prevalence of chronic diseases such as types of cancer, diabetes, obesity and cardiovascular diseases.

Akin to the findings of the present investigation, the results of previous studies involving Japanese-Americans have shown that the foods comprising the Japanese profile were tofu, rice, soy sauce $(s h o y u)$, fish and tsukemono, whereas 
Figure 2

Scores for Japanese (2a) and Western (2b) patterns by generation of Japanese-Brazilians.

2a)

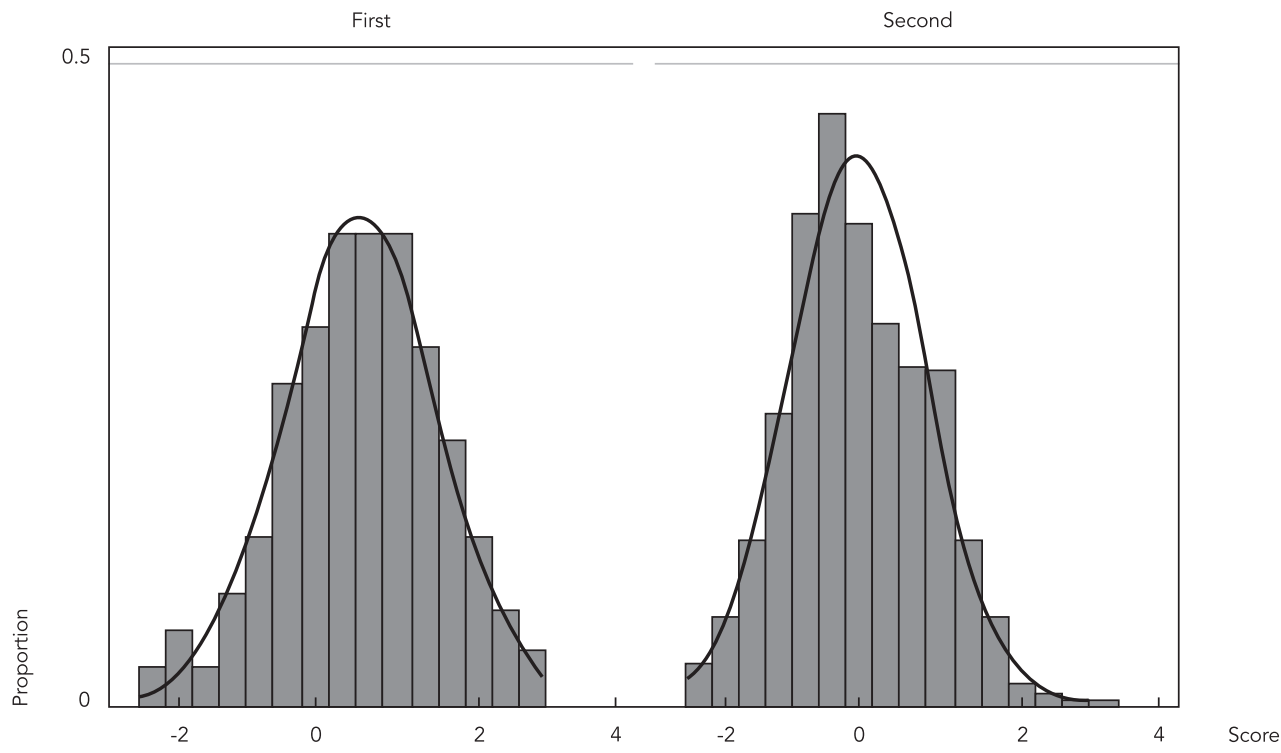

Mean scores: 0.57 vs. -0.14 , for 1 st and 2 nd generations, respectively (t Student test $=10.40 ; p<0.001$ )

2b)

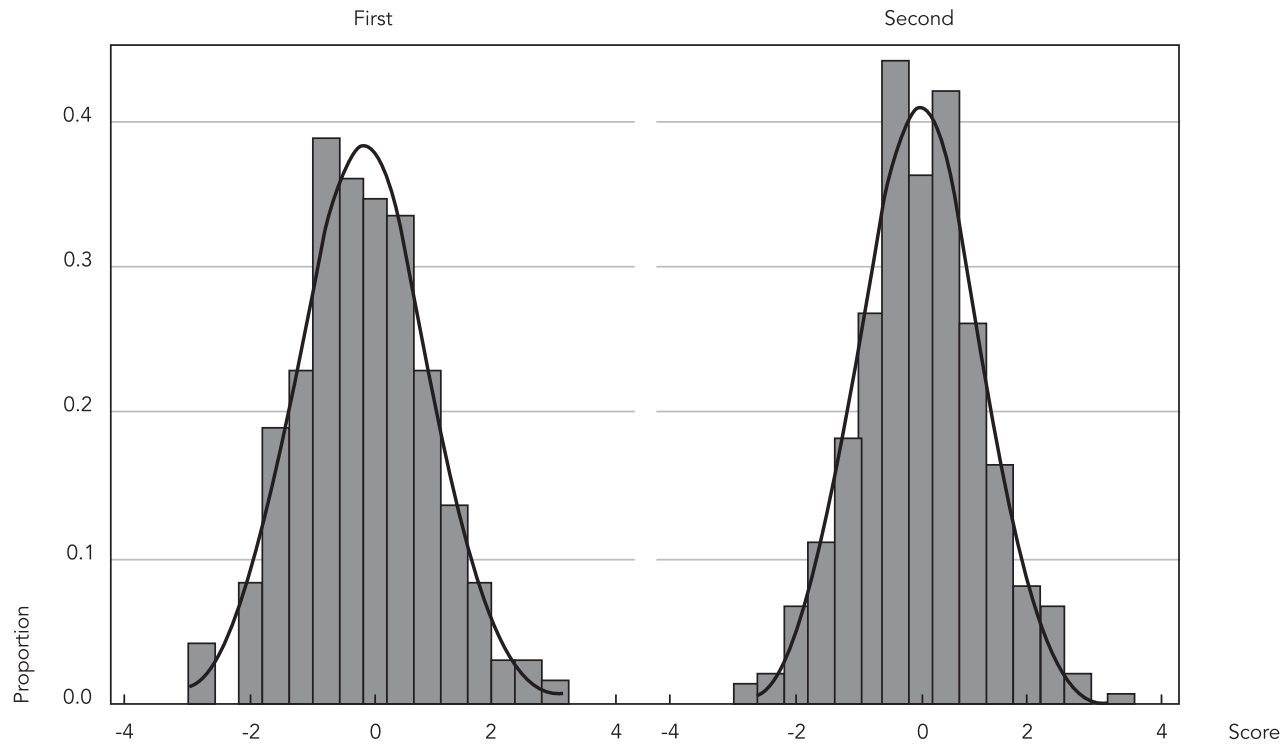

Mean scores: -0.22 vs. 0.05 , for 1 st and $2^{\text {nd }}$ generations, respectively (t Student test $=3.95 ; \mathrm{p}<0.001$ ) 
Results of analyses using multiple models (linear or Poisson) by dependent variables (body mass index - BMI, waist circumference or presence of metabolic syndrome) and independent variables. Bauru, São Paulo, Brazil, 2000.

\begin{tabular}{|c|c|c|c|}
\hline \multirow[t]{3}{*}{ Independent variable } & \multicolumn{3}{|c|}{ Dependent variable } \\
\hline & \multirow{2}{*}{$\begin{array}{l}\text { BMI }\left(\mathrm{kg} / \mathrm{m}^{2}\right) \\
\hat{\beta}(95 \% \mathrm{Cl})\end{array}$} & \multirow{2}{*}{$\begin{array}{l}\text { Waist circumference }(\mathrm{cm}) \\
\qquad \hat{\beta}(95 \% \mathrm{Cl})\end{array}$} & \multirow{2}{*}{$\begin{array}{c}\text { Presence of metabolic } \\
\text { syndrome (yes vs. no) } \\
\text { PR }(95 \% \mathrm{Cl})\end{array}$} \\
\hline & & & \\
\hline \multicolumn{4}{|l|}{ Model 1} \\
\hline Score for Western pattern & $0.46(0.20 ; 0.72)$ & $0.88(0.12 ; 1.63)$ & $1.16(1.04 ; 1.30)$ \\
\hline Gender (male vs. female) & $0.43(-0.15 ; 1.01)$ & $7.85(6.39 ; 9.30)$ & $0.93(0.73 ; 1.13)$ \\
\hline Age (in years) & $0.07(-0.00 ; 0.15)$ & $0.10(0.04 ; 0.17)$ & $1.02(1.01 ; 1.03)$ \\
\hline Generation (first vs. second) & $1.25(0.61 ; 1.89)$ & $2.89(1.03 ; 4.75)$ & $1.44(1.09 ; 1.89)$ \\
\hline Smoking (yes vs. no) & $0.02(-1.83 ; 1.88)$ & $0.00(-1.87 ; 1.88)$ & $1.21(0.94 ; 1.57)$ \\
\hline Physical leisure activity (sedentary vs. non-sedentary) & $-0.15(-0.86 ; 0.56)$ & $-0.25(-2.45 ; 1.98)$ & $0.90(0.69 ; 1.19)$ \\
\hline Years of schooling & $-0.02(-0.22 ; 0.18)$ & $-0.01(-0.22 ; 0.19)$ & $0.99(0.97 ; 1.03)$ \\
\hline Total calories (kcal/day) & $0.00(-0.00 ; 0.01)$ & $0.00(-0.00 ; 0.01)$ & $0.99(0.99 ; 1.00)$ \\
\hline \multicolumn{4}{|l|}{ Model 2} \\
\hline Score for Japanese pattern & $0.08(-0.28 ; 0.44)$ & $0.05(-0.84 ; 0.95)$ & $1.02(0.94 ; 1.10)$ \\
\hline Gender (male vs. female) & $0.52(-0.21 ; 1.25)$ & $7.31(5.50 ; 9.13)$ & $0.84(0.71 ; 0.98)$ \\
\hline Age (years) & $-0.02(-0.05 ; 0.01)$ & $0.08(-0.01 ; 0.16)$ & $1.01(1.01 ; 1.02)$ \\
\hline Generation (first vs. second) & $1.18(0.40 ; 1.96)$ & $2.58(0.63 ; 4.52)$ & $1.21(1.03 ; 1.43)$ \\
\hline Smoking (yes vs. no) & $-0.29(-1.05 ; 0.46)$ & $0.01(-1.87 ; 1.88)$ & $1.13(0.96 ; 1.34)$ \\
\hline Physical leisure activity (sedentary vs. non-sedentary) & $-0.24(-1.12 ; 0.65)$ & $-0.25(-2.45 ; 1.96)$ & $1.00(0.82 ; 1.21)$ \\
\hline Years of schooling & $-0.00(-0.08 ; 0.08)$ & $-0.02(-0.22 ; 0.19)$ & $1.01(0.99 ; 1.02)$ \\
\hline Total calories (kcal/day) & $-0.00(-0.00 ; 0.00)$ & $0.00(-0.00 ; 0.01)$ & $1.00(0.99 ; 1.01)$ \\
\hline
\end{tabular}

PR: prevalence ratio.

the Western profile was made up predominantly of cheeses, soft drinks, savory snacks, chicken and red meat 5 . Similar results were reported by Hu et al. 14 for participants of the Health Professionals Follow-up Study. Using factor analysis, these authors identified a "prudent" profile characterized by a high habitual intake of vegetables, fruit, whole cereals and fish, while the Western pattern had a higher proportion of processed meats, red meat, butter, milk derived products and refined cereals.

It is known that, among migrant groups, the process of incorporating new habits and customs has different and complex degrees of ethnic and cultural differentiation, where some individuals identify with multiple cultures at the same time. Habitual diet is one of the components of life style that can reflect these processes. The present study, similarly to that carried out by Pierce et al. 5 , demonstrated that subjects of both generations had altered their traditional life-style (Japanese) to some extent, as evidenced by the distribution of dietary scores (Figure 2). These changes were found to be more frequent among second generation Japanese.

Assessing dietary intake patterns in epidemiological studies investigating the role of diet in developing chronic diseases offers advantages over traditional approaches which take into account solely the intake of nutrients. Hu $15 \mathrm{em}$ phasized that this novel approach, besides more closely reflecting reality, helps devise feasible strategies for disease prevention and treatment. However, the author points out that this type of procedure has inherent limitations, such as the need for instruments which are able to identify these patterns yet do not invalidate traditional analyses, which may be run in parallel.

A number of different procedures for identifying patterns of dietary intake are cited in the literature such as factor analysis, cluster analysis and diet quality index. Regardless of which strategy is elected, their respective limitations in interpreting results must not be overlooked. For instance, because factor analysis is based on correlations amongst variables, no separate causal inference 
can be made. Moreover, the results obtained depend on the characteristics (validity and reproducibility) of the instrument used, in this case the FFQ. Other aspects such as sample size (recommended minimum of 5 subjects per variable of interest) are also a factor. A further proportion e.g. $20 \%$, should be added to the sample in order to guarantee the analysis (even after losses) and its representativity (values of variables may be sample-specific) $7,8,15$.

Data for the present study were collected using a FFQ with a good degree of validity and reproducability ${ }^{9}$ which served to minimize poten- tial errors. Although the results are representative of a Brazilian-Japanese community, the data may not apply to other Japanese communities.

Based on the results of this study, we can conclude that factor analysis enabled identification of profiles and was effective in discriminating subjects who maintained their traditional Japanese lifestyle from those that had introduced typically Western foods to their diets. In addition, incorporation of Western habits was found to correlate positively with BMI, waist circumference and metabolic syndrome in this group of Japanese-Brazilians.

\section{Resumo}

Descreve-se o uso da análise fatorial na avaliação dos hábitos alimentares de nipo-brasileiros. Utilizaramse dados dietéticos de 1.283 participantes de estudo transversal. A partir de critérios estatísticos e do significado conceitual dos padrões identificados, geraram-se escores que definiram os perfis dietéticos (japonês ou ocidental). Empregou-se o teste t de Student pareado, os modelos de regressão linear e de Poisson para examinar as relações desses escores com, respectivamente, a geração, índice de massa corporal (IMC), perímetro abdominal e a presença de síndrome metabólica. Aqueles de primeira geração, em relação aos de segunda, apresentaram escores maiores para o perfil japonês e menores para o ocidental. O perfil ocidental relacionou-se com o IMC $(p=0,001)$, perímetro abdominal $(p=0,023)$ e a síndrome metabólica $(p<0,05)$. Conclui-se que os escores discriminaram sujeitos que mantêm ou não estilo de vida tradicional japonês e que a incorporação de hábitos ocidentais associou-se a maiores valores de IMC, perímetro abdominal e a presença de síndrome metabólica.

Hábitos Alimentares; Epidemiologia Nutricional; Nipo-Brasileiros; Análise Fatorial

\section{Contributors}

S. G. A. Gimeno was involved in the planning of the study, and the collection, analysis and interpretation of data, as well as the writing of the manuscript. S. Andreoni worked on data analysis and interpretation, as well as the review of the manuscript. S. R. G. Ferreira and L. J. Franco assisted in the data collection and manuscript review. M. A. Cardoso was involved in the planning of the study, in data collection and review of the manuscript.

\section{Acknowledgments}

The authors would like to thank the São Paulo State Research Foundation (FAPESP) for providing financial support for this study (grant process no. 98/04178-7). 


\section{References}

1. World Health Organization. Report of a Joint WHO FAO Expert Consultation. Diet, nutrition and prevention of chronic diseases. Geneva: World Health Organization; 2003. (WHO Technical Report Series, 916).

2. Fujimoto WY, Leonetti DL, Kinyoun JL, NewelMorris L, Shuman WP, Stolov WC, et al. Prevalence of diabetes mellitus and impaired glucose tolerance among second generation Japanese-American men. Diabetes 1987; 36:730-8.

3. Gimeno SGA, Ferreira SRG, Franco LJ, Hirai A Matsumura L, Moisés RCS, et al. Prevalence and 7-year incidence of type 2 diabetes mellitus in a Japanese-Brazilian population: an alarming public health problem. Diabetologia 2002; 45:1635-8.

4. Nakamura M, Whitlock G, Aoki N, Nakashima T, Hoshino T, Yokoyama T, et al. Japanese and Western diet and risk of idiopathic sudden deafness: a case-control study using pooled controls. Int J Epidemiol 2001; 30:608-15.

5. Pierce BL, Austin MA, Crane PK, Retzlaff BM, Fish B, Hutter CM, et al. Measuring dietary acculturation in Japanese-Americans with the use of confirmatory factor analysis of food frequency data. Am J Clin Nutr 2007; 86:496-503.

6. Freire RD, Cardoso MA, Gimeno SGA, Ferreira SRG. Dietary fat is associated with metabolic syndrome in Japanese Brazilians. Diabetes Care 2005; 28:1779-85.

7. Suhr DD. Exploratory or confirmatory factor analysis? Cary: SAS Institute; 2006.
8. Mardia KV, Kent JT, Bibby JM. Factor analysis. In: Mardia KV, Kent JT, Bibby JM, editors. Multivariate analysis. San Diego: Academic Press; 1979. p. 25580.

9. Cardoso MA, Kida AA, Tomita LY, Stocco PR. Reproducibility and validity of a food frequency questionnaire among women of Japanese ancestry living in Brazil. Nutr Res 2001; 21:725-33.

10. International Diabetes Federation. The IDF consensus worldwide definition of the metabolic syndrome. Brussels: International Diabetes Federation; 2006.

11. Nunnally JC. Psychometric theory. 2nd Ed. New York: McGraw-Hill; 1978.

12. Cattell RB. The scree test for the number of factors. Multivariate Behav Res 1966; 1:245-76.

13. World Health Organization/Food and Agriculture Organization. Diet, nutrition and the prevention of chronic diseases. Geneva: World Health Organization; 2002.

14. Hu FB, Rimm E, Smith-Warner SA, Feskanich D, Stampfer MJ, Ascherio A, et al. Reproducibility and validity of dietary patterns assessed with a foodfrequency questionnaire. Am J Clin Nutr 1999; 69:243-9.

15. Hu FB. Dietary pattern analysis: a new direction in nutritional epidemiology. Curr Opin Lipidol 2002; 13:3-9.

Submitted on $15 /$ Jun/2009

Final version resubmitted on 15/Nov/2009

Approved on 11/Feb/2010 